\title{
AUTOBIOGRAFÍA / AUTOFICCIÓN EN EL ÁMBITO HISPÁNICO. FRONTERAS Y ESTUDIOS RECIENTES ${ }^{1}$
}

\author{
AUTOBIOGRAPHY / AUTOFICTION IN THE HISPANIC AREA. \\ FRONTIERS AND RECENT STUDIES
}

\author{
Álvaro LUQUE AMO \\ Universidad de Córdoba \\ alvaro.luque@uco.es
}

\begin{abstract}
Resumen: En la teoría literaria sobre escritura autobiográfica y autoficcional ha predominado cierta confusión en el empleo de las etiquetas y solamente en los últimos años parece haberse generalizado una distinción definitiva entre ambos discursos narrativos. Este artículo tiene como objetivo establecer un recorrido de la evolución experimentada por la dicotomía autobiografía / autoficción. Para ello, parto de los orígenes de lo autoficcional, analizo la evolución de este debate y finalmente me centro en las últimas publicaciones de relevancia. La intención es dar a conocer nuevas ideas, todavía poco discutidas en el ámbito hispánico, que desarrollan y amplían los planteamientos de autores asentados en este campo de estudio.
\end{abstract}

Palabras clave: Autobiografía. Autoficción. Teoría de la autobiografía. Literatura española contemporánea. Autonarración.

\begin{abstract}
In the literary theory on autobiographical writing and autofiction, there has been a certain degree of confusion in the use of labels; only recently, a clear distinction has been drawn between them both. This article aims to establish a path of evolution for the dichotomy autobiography / autofiction. I will start from the origins of autofiction, will later analyse the evolution of the theoretical debate, and will finally focus on the latest relevant publications. Therefore, the article will make known new ideas, still little discussed in the Hispanic sphere, which develop and extend the approaches of authors based in this field of study.
\end{abstract}

Keywords: Autobiography. Autofiction. Theory of Autobiography. Contemporary Spanish Literature. Self-narration.

\footnotetext{
${ }^{1}$ Este trabajo se ha realizado bajo el patrocinio de una Ayuda para Contratos Juan de la Cierva-formación concedida por el Ministerio de Ciencia, Innovación y Universidades [FJC2019-040570-I]. Se vincula, además, a dos proyectos de investigación con financiación estatal: "Biografías y polémicas: hacia la institucionalización de la literatura y el autor (SILEM II)" [RTI2018-095664-B-C21] y "Procesos de subjetivación: biopolítica y política de la literatura. La herencia del primer M. Foucault" [PID2019107240GB-I00].
} 
La relación que se establece naturalmente entre texto autobiográfico y ficción literaria es problemática desde los orígenes de las escrituras del Yo. En una fecha tan temprana como 1906, Stephen Reynolds acuña el término autobiografiction, que resulta de una modernidad notable, y lo hace para etiquetar una obra que, según su punto de vista, debe situarse entre el espacio autobiográfico y el espacio ficcional (Reynolds, 1906) ${ }^{2}$. Más allá de la aplicabilidad del neologismo, coincidente en algunos puntos con etiquetas que se expondrán después, hay que destacar su conciencia del ámbito autobiográfico como un espacio difuso y movedizo desde ese mismo momento. Una metáfora que se ha empleado en muchas ocasiones para definir este lugar es la de la frontera. En los estudios literarios españoles, Pozuelo Yvancos habla de la frontera que separa los géneros autobiográficos del sistema literario para incidir en la permeabilidad de los primeros (Pozuelo Yvancos, 1993: 179), y Manuel Alberca vuelve a utilizar tal imagen para titular un artículo de 1999 (Alberca, 1999), lo que viene a arrojar luz sobre los complejos vínculos entre autobiografía y literatura entendida como terreno de la ficción literaria.

Esta complejidad se evidencia en los años setenta del pasado siglo, cuando Lejeune escribe sus grandes obras sobre escritura autobiográfica, surge el concepto de autoficción en la obra de Serge Doubrovsky, Fils, y además Paul de Man problematiza la idea misma del género autobiográfico desde la teoría deconstruccionista. Como se ha escrito mucho al respecto, y más abajo me ocuparé de estos fenómenos, me limitaré ahora a señalar que es justo a partir de estos años 70 y 80 , y más concretamente a finales del siglo XX y principios del XXI, el momento en que la etiqueta autoficción protagoniza una moda tanto literaria como académica en casi todos los contextos occidentales, circunstancia que favorece la confusión entre autobiografía y autoficción $-\mathrm{y}$, por derivación, entre autobiografía y ficción-. En los últimos años existen bastantes autores que han alertado sobre la decadencia de esta moda ${ }^{3}$, y en paralelo a este declive también puede localizarse una tendencia a diferenciar entre el terreno de la escritura autobiográfica y la autoficcional, si bien es cierto que en el ámbito de los estudios sobre escritura autobiográfica ha habido, por lo general, una acusada diferenciación, como lo demuestra el trabajo realizado por José Romera Castillo en su grupo de investigación SELITEN@T, de la UNED ${ }^{4}$. Este último proceso es especialmente acusado en el ámbito internacional,

\footnotetext{
${ }^{2}$ El primer autor en tratar este temprano caso ha sido Max Saunders en su artículo "Autobiografiction: Experimental Life-Writing from the Turn of the Century of Modernism" (Saunders, 2009). En el presente trabajo, por falta de espacio, no se profundizará en este interesante artículo, ni tampoco en este concepto de autobiograficción, que sin embargo puede coincidir con otras etiquetas explicadas.

${ }^{3}$ Ya Manuel Alberca en 2009, en el artículo que titula precisamente "Autobiografía vs. Autoficción", define lo autoficcional como una "moda posmoderna, ya demodée" (Alberca, 2009: 6), lo que también sugiere Ana Casas en 2012 (Casas, 2012: 40). En 2017 Anna Caballé publica una reseña titulada "¿Cansados del yo?", en donde advierte de los "síntomas de fatiga" de lo autoficcional (Caballé, 2017), y en 2019 Vicente Luis Mora incide en este agotamiento, ya repetido hasta la saciedad, para ampliarlo al conjunto de las escrituras del Yo en su ensayo La huida de la imaginación (Mora, 2019).

${ }^{4}$ Véase: https://www2.uned.es/centro-investigacion-SELITEN@T/escritura_autobio.html[04/03/2021].

Un artículo que resume el amplio corpus de publicaciones de este grupo de investigación es "La escritura
} 
en donde destaca la publicación en 2019 de una obra de gran relevancia como es Autobiographie / autofiction, una suerte de enciclopedia colectiva coordinada por Martina Wagner-Egelhaalf (De Gruyter, 2019) y en la que se da por evidente esta distinción.

En el presente artículo me propongo como objetivo principal establecer un repaso de la evolución de esta dicotomía autobiografía / autoficción. Para ello parto de los orígenes de lo autoficcional, situándome en la célebre publicación de Doubrovsky, y después me centro en las últimas publicaciones - que considero de relevancia— sobre esta cuestión. La intención es dar a conocer ciertas ideas, todavía casi desconocidas y poco discutidas en el ámbito hispánico, que desarrollan y amplían los planteamientos de autores muy asentados en los estudios sobre autobiografía y autoficción. Por este último motivo, incluyo al final de este trabajo unas largas conclusiones en las que busco resumir, explicar y asentar ideas que, en definitiva, favorecen la aclaración de estas fronteras inevitables entre texto autobiográfico, ficción y texto autoficcional.

\section{EL ORIGEN DE LA AUTOFICCIÓN. LA CARTA DE DOUBROVSKY A LEJEUNE}

Resulta curioso que en el amplio corpus de los estudios literarios en español que se le viene dedicando en las dos últimas décadas a la literatura autoficcional, y sobre todo entre aquellos análisis que más específicamente se centran en la genealogía del concepto, no abunden los acercamientos que remitan a un hecho biográfico de bastante interés para la evolución de esta categoría. Me refiero a una carta que el entonces relativamente desconocido Serge Doubrovsky envía a Philippe Lejeune para explicarle sus consideraciones acerca del concepto de pacto autobiográfico y en la que se revelan algunas claves de interpretación que pueden ayudar a diferenciar la naturaleza de ambos tipos de textos, autoficcionales y autobiográficos.

Se trata de una carta fechada en 1977 que el propio Lejeune incluye en Moi aussi (1986), donde revisa y amplía ideas de su célebre ensayo publicado en 1975, Le pacte autobiographique, y en la que expone el origen de su empresa. Por su relevancia para este punto, paso a exponer íntegro el fragmento que incluye Lejeune en su libro:

Recuerdo que, al leer hace tiempo en Poetique su estudio, marqué el pasaje (que acabo de volver a encontrar): “¿El héroe de una novela declarada como tal puede tener el mismo nombre que el autor? Nada lo impediría, pero en la práctica no nos encontramos con ningún ejemplo". En aquella época estaba escribiendo mi libro y aquello me influyó, me llamó profundamente la atención. Incluso ahora, sigo teniendo mis dudas sobre el carácter teórico de mi trabajo. No soy yo quien deba decidirlo, pero intenté llenar aquella "casilla"

(auto)biográfica y el SELITEN@T: guía bibliográfica" (Romera Castillo, 2010), que compila el trabajo hecho en otros grandes trabajos, ya convertidos en canónicos, como es el primero dedicado al ámbito autobiográfico en el contexto español (Romera Castillo, 1981) y otros posteriores (Romera Castillo, 1991; 1999; 2006 y Romera Castillo et alii, 1993). Recientemente, en el seno de este grupo se ha publicado un libro en el que se analizan obras teatrales de carácter autobiográfico y autoficcional y en el que se muestra esta diferencia en el propio título (Laín Corona y Santiago Nogales, eds., 2019). 
que su análisis dejaba vacía, y fue como un impulso que de repente me hizo relacionar su texto crítico con lo que estaba escribiendo, si no a ciegas, al menos en una semioscuridad... (Lejeune, 1994: 178).

Generalmente, se ha asociado el comienzo de la autoficción con este momento, el instante en que Doubrovsky se ve impelido por el texto de Lejeune como si se tratase de un reto. Como es sabido, en ese primer libro Lejeune desarrolla los elementos constitutivos del pacto autobiográfico, y al hacerlo se plantea la existencia de un tipo de obra que, siendo ficcional, incluye una narración en la que se identifican autor, narrador y personaje protagonista. Lo llamativo de esa definición es que, al mismo tiempo, Lejeune dice no recordar ninguna obra en la que esto último suceda, de tal modo que habilita el reto de Doubrovsky, quien, como señala más arriba, intenta rellenar aquella casilla con Fils, la novela que publica en 1977, mismo año de la carta.

En un rápido vistazo a Fils, se puede encontrar un libro en el que se retrata un día en la vida de un tal Serge Doubrovsky, que se llama igual que el autor y que acude a una sesión de psicoanálisis a través de la que sus pensamientos son escrutados en una suerte de monólogo interior al estilo de las novelas modernistas. La innovación, lo verdaderamente destacable, por tanto, es la identificación que existe entre autor, narrador y personaje, y la ambigüedad que el texto sugiere al lector. El nivel de antigüedad es tal que hasta el propio Lejeune, como testimonia (Lejeune, 1994: 182), no capta los elementos ficcionales hasta terminada su lectura y una vez accede a todo tipo de paratextos y comentarios sobre la obra. La razón de ello es que Doubrovsky pretende jugar en todo momento con las posibilidades ficcionales de su autobiografía: como señala en la contraportada, no se considera poseedor de la suficiente importancia para escribir ya una autobiografía, "privilegio reservado a los importantes de este mundo" (Doubrovsky, 2001: 10), por lo que presenta una narración de hechos reales. ¿Dónde radica la ficción? En la sesión de psicoanálisis, que, como el propio autor reconoce en un artículo posterior, es inventada. Se trata del marco del ficcional a partir del cual el narrador desarrolla un texto aparentemente referencial.

Ahora bien, de la misma forma en que lo autobiográfico parece ser desafiado, cabe preguntarse si ese marco es suficiente para considerar el texto como una autoficción, y aquí es donde tiene sentido volver a la carta. Para empezar, debe partirse del carácter plenamente autoconsciente de la empresa de Doubrovsky, quien, como señala Gasparini (2011: 12), ya había ejercido la crítica literaria y publicado ensayos de envergadura, y además inscribía su pensamiento literario en un determinado contexto. Es este último el propio de los años setenta en Francia, en los años dorados del posestructuralismo y en donde imperan las tesis, de Barthes y Foucault entre otros, que cuestionan la figura del autor y su prevalencia en la crítica. En esta línea se entiende además la llegada del Nouveau Roman, grupo de autores que desafiaban el relato tradicional - y con él sus componentes, como el autor- a partir de textos experimentales. Precisamente debe

\footnotetext{
${ }^{5}$ La traducción es mía.
} 
señalarse, por un lado, la posible influencia en Doubrovsky de Barthes, que como señala Pozuelo Yvancos (2010: 14) publica dos años antes de Fils su contra-autobiografía particular, y sobre todo la del Nouveau Roman, pues el propio Doubrovsky va a reconocer la presencia de este último movimiento en el inicio de su novela (Doubrovsky, 2012: 51).

Todo lo anterior proporciona un caldo de cultivo idóneo para que entre 1975 y 1977, tal y como cuenta en la carta, Doubrovsky intente rellenar la casilla de Lejeune, como además confiesa en el texto teórico que publica dos años más tarde: “¡Es como si Fils hubiese sido escrita para llenar esa casilla vacía!" (Doubrovsky, 2012: 52). Esta declaración se produce en el contexto de su artículo, en el que intenta responder por qué, a pesar de su intento por ofrecer un texto autobiográfico, este termina convirtiéndose en una autoficción. Después de analizar pormenorizadamente Fils, Doubrovsky llega a las propias claves de interpretación que, desde mi punto de vista, mejor explican la naturaleza de lo autoficcional. Según él, y aunque haya intentado construir un texto a partir de su vida para introducir solamente un marco ficcional que a priori no afecta al testimonio, el impulso psicoanalítico convierte el discurso de Fils en una especie de autoensayo metaliterario en el que, como señala, "el sentido de la vida no está en ninguna parte, no existe" (Doubrovsky, 2012: 53). Es decir: por mucho que los hechos reales que introduce sean biográficos, hayan ocurrido en el plano referencial, esto pasa a un segundo plano para ser sustituido por una voz autodiscursiva que solamente practica, ensaya - por eso se asemeja tanto al ensayo sobre uno mismo o autorretrato- y construye un flujo de pensamiento que en realidad permanece en casi todo momento en un plano metaliterario. Por esta razón, muchos investigadores inciden en el carácter metaliterario de lo autoficcional que, si bien se puede extrapolar igualmente al resto de textos autobiográficos — pues muchos de ellos incorporan una vertiente metadiscursiva—, en el primer ámbito va a acompañado además de un tono claramente humorístico. El autor se ríe de todos, para empezar de sí mismo, y al hacerlo construye ese texto "poco serio" que es la autoficción en los términos empleados por Marie Darrieussecq (2012) para definirla.

En suma, puede acudirse a esta carta, así como al texto de Doubrovsky de tres años después, para comprobar que el ecosistema propicio para el surgimiento de la autoficción solo se pudo construir en relación con el campo autobiográfico y, por extensión, con las teorías de Lejeune sobre el pacto autobiográfico. El supuesto eslogan según el cual Doubrovsky no se considera lo suficientemente prestigioso para escribir un texto autobiográfico en realidad camufla un intento de otorgar a su texto el prestigio que implica un estatus ficcional. Como argumenta Arnaud Schmitt (2010: 123), es muy posible que las novelas autobiográficas surgieran de un deseo del autor por disfrutar del creciente estatus de los escritores de ficción, y en esta línea cabe entender el impulso autoficcional de Doubrovsky. A su vez, y lo que es más importante ahora, establece desde sus orígenes una diferenciación clara entre autobiografía y (auto)ficción. 


\section{DE LA AUTOFICCIÓN A LA AUTOBIOGRAFÍA (CON ESCALAS EN LA ANTIFICCIÓN Y LA AUTONARRACIÓN)}

Lo que acontece después de 1977, y una vez empiezan a aparecer tanto textos literarios como científicos que versan sobre el tema, ha sido ya resumido en la introducción. En 1989 se defiende la primera tesis sobre autoficción, la de Vincent Colonna, y a partir de ese momento los estudios se multiplican en el ámbito europeo, con especial incidencia, claro está, en el ámbito francés. Esta proliferación se debe al contagio científico, pero sobre todo al carácter de lo autoficcional como un concepto que alude a manifestaciones con una existencia previa. El propio Lejeune reconoce en su revisión del pacto autobiográfico su ceguera al no reparar en ejemplos para rellenar su casilla en blanco - por ejemplo, Lecarme propone textos de Barthes, Malraux o Celine (Lecarme, 1984) - y en los años 80 proliferan los textos que experimentan de una forma u otra con los componentes esenciales del contrato autoficcional. Por poner un caso como el de la literatura española, más cercano a nosotros, en los años 1986 y 1987, Félix de Azúa publica dos textos, Historia de un idiota contada por él mismo y Diario de un hombre humillado respectivamente, que Alberca incluye dentro de lo autoficcional por cuanto en ellos el autor "alude y no alude a sí mismo" (Alberca, 2007: 238) — hay que aclarar, no obstante, que se trata de una estructura que empleó ya Azorín en su Diario de un enfermo en la temprana fecha de 1901 - y en el mismo 1987 Javier Marías esboza una idea reveladora en su breve ensayo "Autobiografía y ficción”, cuando encuentra un tipo de escritor que, al abordar este debate, recuerda mucho al autor de la autoficción:

[...] este tercer tipo de escritor, al presentar su texto como ficción pero no hacer nada para ficcionalizarlo, lo que quizá está haciendo es indicar ambas cosas a la vez. Es decir, que lo relatado le sucede a él, el autor, y al mismo tiempo no le sucede a él, el autor, en la medida en que en realidad no ha sucedido, ni a él ni a nadie en absoluto; aunque en la medida en que sucede en su obra de ficción, sea a él, el autor, y a nadie más a quien sucede. [...] creo que es en esta delicadísima fórmula donde se encuentra la posibilidad de acometer la empresa que, como antes dije, cada vez me tienta e interesa más a pesar de mis comienzos y mi novela primera que la eludió tan tajantemente: abordar el campo autobiográfico, pero solo como una ficción (Marías, 2001: 78).

Aquí ya están todas las claves de este concepto, y va a ser solamente dos años después, en 1989, cuando Javier Marías publique Todas las almas, que además de ser una de las grandes obras de la literatura española contemporánea incluye en su construcción evidentes rasgos de una poética autoficcional, pues, como señala Alberca, es una obra que tiene valor por "su estatus narrativo ambiguo: no ser ni autobiografía ni novela o ser ambas cosas a la vez de manera transgresiva" (Alberca, 2007: 136). Si Marías lleva a cabo esta empresa cuando el término autoficción todavía no ha ocupado gran parte de los debates académicos, se debe a la capacidad del concepto para dar nombre a algo que ya estaba ahí y solo necesitaba ser designado. A partir de los años 90, y a lo largo de esta década y la primera del siglo XXI, el término aparece en tantas ocasiones y aplicado a 
tantas fórmulas que rápidamente se distorsiona su naturaleza. Una naturaleza que, por si fuera poco, no está clara desde su origen y, a semejanza de otros términos como el de posmodernidad, destaca por su maleabilidad, lo que la conduce rápidamente a convertirse en un cajón de sastre ${ }^{6}$. Esta última característica es, claro, un arma de doble filo: por un lado permite su utilización en muchos tipos de textos y, derivada de ello, un crecimiento rápido y exitoso en todos los ámbitos — después de que Pedro Almodóvar la haya utilizado textualmente en su última película, Dolor y gloria (2019), apenas quedan espacios culturales en donde no se frecuente la categoría-; por otro, propicia la inexactitud del término, que se convierte poco a poco en una etiqueta incapaz de concretar el ámbito de su definición.

A esto último se le añade, y tal vez sea una de las circunstancias más relevantes, el deseo de ciertos autores por emborronar las diferenciar entre autobiografía y ficción. No hay que olvidar, como se ha dicho más arriba a propósito de las circunstancias en que Doubrovsky escribe Fils, que estos son los años dorados del posestructuralismo, contexto en el que destacan las teorías deconstruccionistas de Derrida según las cuales todo texto puede ser interpretado como una ficción. Es lo que intenta resumir Ana Casas en la introducción a su importante antología sobre autoficción de 2012, cuando se refiere a la "quiebra de confianza en el discurso autobiográfico" (Casas, 2012: 16) que evidencian las posiciones de muchos autores, capitaneados por las teorías escépticas sobre el pacto autobiográfico de Paul de Man, quien en su célebre artículo de 1979 cuestiona la capacidad referencial del texto autobiográfico (De Man, 1991). Como esta dicotomía se ha repetido y analizado en numerosas ocasiones, me remito ahora a rastrear el influjo que las hipótesis deconstruccionistas tienen en la evolución de lo autoficcional. Entre ellas es destacable, como señala Ana Casas (2012: 16), la posición de los trabajos recopilados en Autobiographie und Avant-garde, pero también se intuye en las aproximaciones a este campo de autores como Marie Darrieussecq, que de entre las posibles virtudes del discurso autoficcional destaca su capacidad de "poner en cuestión la práctica ingenua de la autobiografía" (Darrieussecq, 2012: 82), y en muchos análisis fechados en las últimas décadas en los que obras de carácter autobiográfico son tachadas de autoficciones. Vincent Colonna señala en 2004 que "con frecuencia, se oyen barbaridades en las que autoficción y autobiografía funcionan como sinónimos" (Colonna, 2012: 45), y más recientemente, en 2018, Helena Corbellini testimonia con ironía esta malinterpretación en su país: "entiendo que solamente en Uruguay la crítica confunde autobiografía con autoficción" (Corbellini, 2018).

Cuando en años muy recientes — quizás se podría hablar de la segunda década del siglo XXI - la moda autoficcional decae, como se ha visto más arriba, se constatan sus diferencias respecto a la vieja etiqueta de autobiografía. Utilizo el verbo constatar porque, como se ha podido comprobar, numerosos autores han incidido desde su origen en las evidentes diferencias: aparte del citado Vicent Colonna, y por aludir a los teóricos más

\footnotetext{
${ }^{6}$ Tanto Manuel Alberca (1996: 11) como Ana Casas (2012: 10-11) alertan sobre esta confusión.
} 
importantes, Philippe Gasparini hilvana su concepto de autonarración —recogido de Arnaud Schmitt (2005) — precisamente a raíz de esta distinción, y Manuel Alberca protagoniza una evolución muy clara desde sus primeras posiciones, a partir de las que se interesaba por los textos autoficcionales, a las últimas, en las que reniega tajantemente de este tipo de escritura. Otros autores en nuestro contexto acatan igualmente la distinción desde una fecha relativamente temprana, como es el caso de Alicia Molero (2006). ¿Cuál es la razón de que a pesar de existe algo similar a un consenso teórico se siga produciendo la citada confusión entre autobiografía y autoficción? Posiblemente se deba, como acabo de desarrollar un poco más arriba, al propio éxito del término y su efecto en la mercadotecnia literaria. Lo que explica además que muchos de los autores citados escriban, en los últimos años, textos destinados exclusivamente a diferenciar entre ambas categorías, y aquí es donde radica la novedad del presente artículo, que sirve como recopilación de algunos ejemplos de este tipo de textos.

Uno de estos textos, por ejemplo, es el que publica Philippe Gasparini en 2011 con el título "Autofiction vs autobiographie". Allí establece un recorrido por determinados textos autoficcionales que, según él, muestran que la autoficción solo puede definirse a través de una crítica de la autobiografía (Gasparini, 2011: 11). Los textos que escoge Gasparini intentan describir el texto autobiográfico puro como "un objeto malo, inmoral y prosaico $7 "$ (Gasparini, 2011: 24), y en definitiva evidencian el origen de lo autoficcional, desde la propia empresa de Doubrovsky a la que se refiere, como subversión, y no exactamente como descendiente, de lo autobiográfico, por eso debe evitar la "contaminación" (Gasparini, 2011: 24) del discurso referencial.

Desde una perspectiva totalmente opuesta, Manuel Alberca ha protagonizado el citado viraje desde su elogio de lo autoficcional a lo que él mismo denomina como un cansancio del género. Alberca, experimentado conocedor de la bibliografía francesa, ha ganado celebridad por introducir, en fecha de 1996, el concepto de autoficción en España al recogerlo en su artículo titulado "El pacto ambiguo". Este trabajo es el germen de la que ha sido la monografía sobre esta cuestión con más relevancia en la bibliografía española. Me refiero a El pacto ambiguo. De la novela autobiográfica a la autoficción, publicado en 2007 en Biblioteca Nueva, en donde lleva a cabo un profundo análisis del fenómeno, elabora una taxonomía avanzada de las manifestaciones relacionadas con lo autoficcional y en general establece el diagnóstico de un nuevo género de la literatura española reciente. Lo llamativo de esta primera etapa es que si Alberca en 1996 trata lo autoficcional como un fenómeno de interés, y el tono que utiliza es analítico - aunque ya asume que este discurso es "una manera de emborronar la clara y explicativa teoría de Ph. Lejeune" (Alberca, 1996: 10)_, en 2007 ya es consciente de los posibles excesos a los que puede conducir este tipo de escritura, pues se mantiene "prudencialmente a distancia de lo que suponga algo más que responsabilidad estética ante los lectores" y renuncia "al riesgo de autoconocimiento y/o al compromiso que conlleva la exposición pública” (Alberca, 2007:

\footnotetext{
${ }^{7}$ La traducción es mía.
} 
290-291). Esta ausencia de riesgo es la que conduce al mismo Alberca, en 2009, a señalar que la autoficción se caracteriza por avalar "un individualismo a la carta y un ludismo sin riesgo" (Alberca, 2009: 24), y en 2014, a escribir un texto como "De la autoficción a la antificción. Una reflexión sobre la autobiografía española actual”, en el que emite su ya célebre frase sobre el agotamiento de lo autoficcional - "me cansa ya la autoficción, y los años comienzan a darme una visión más serie de la literatura" (Alberca, 2014: 149)_ y que a su vez es preámbulo del último de sus ensayos, publicado en 2017: La máscara o la vida. De la autoficción a la antificción. Me he detenido en este ensayo en varios trabajos, por lo que paso a resumir su intención fundamental. Esta no es otra que diferenciar definitivamente entre aquellos textos, autoficcionales, que huyen del compromiso de veracidad al que nos referimos desde los preceptos de Lejeune, y aquellos otros que a falta de mejor término Alberca denomina como antificcionales, en los que el autor muestra una "predisposición literaria a contar la verdad y solo la verdad, que excluye radicalmente la libertad o tentación de inventar que pueden tener algunos autores de la autoficción" (Alberca, 2017: 322). El concepto de antificción lo toma Alberca de un texto de Lejeune fechado en 2007 —en el que este utiliza tal noción para referirse a la inmediatez del diario personal (Lejeune, 2007) — y resume las posiciones de aquellos autores que desafían los preceptos posmodernos según los cuales es imposible construir un texto que mantenga lazos referenciales con la realidad, así como la de aquellos otros que centran la perspectiva de lo autobiográfico en el contrato ético sostenido entre autor y lector, como es el caso de Ángel Loureiro (2016).

Tanto la posición de Gasparini como la de Alberca, si bien desde coordenadas diferentes, evidencian la distancia que media entre los conceptos de autoficción y autobiografía. A sus trabajos se les suman además las investigaciones de otros dos estudiosos, Arnaud Schmitt y Vera Toro, que se han incorporado al debate de forma más reciente y cuyas posiciones iluminan las diferencias a las que me vengo refiriendo.

\subsection{Arnaud Schmitt: autonarración / autoficción}

Arnaud Schmitt es un investigador y profesor de la Université de Bordeaux que ha seguido desde 2005 una trayectoria en la que, partiendo de téoricos asentados en el campo de la autoficción como Gasparini, lleva estas teorías a otro contexto, dentro del cual ha publicado varios de los trabajos más interesantes sobre autoficción y una nueva forma que él ha preferido denominar autonarración.

Para abordar el pensamiento de Schmitt sobre este tema, y aunque acuña el concepto en un temprano artículo de 2005 (Schmitt, 2005), lo ideal es remontarse al artículo que publica en 2010 con el título "Making the Case for Self-Narration Against Autofiction" y que he citado en una ocasión más arriba. En este trabajo, Schmitt repasa las diferentes denominaciones que se le han dado a la ficción autobiográfica tanto en el contexto anglosajón como el francés, y en ese recorrido esboza algunas de las ideas más importantes para entender esta diferenciación definitiva entre autobiografía y autoficción 
que propongo. Para empezar, Schmitt se sitúa en un terreno neutro respecto a las escrituras autobiográficas: si por un lado afirma que, como señala Marie Darrieusecq, tendría cierto sentido introducir a la autobiografía "en el club de la ficción " "Schmitt, 2010a: 127), por otro señala que lo autobiográfico posee un carácter ético difícilmente soslayable. Asumiendo las características paradójicas de lo autobiográfico, Schmitt busca con su término autonarración definir "una tendencia específica (y reciente) de las narraciones autobiográficas" (Schmitt, 2010a: 133). En este sentido, y como amplía en "De l'autonarration à la fiction du réel: les mobilités subjectives" (Schmitt, 2010b), su idea es concebir la autonarración como "una salida a la monotonía autobiográfica" (Schmitt, 2010b) en la medida en que, según su perspectiva, lo autobiográfico ha devenido una forma mil veces repetida y poco original, y para ello no duda en concebir el texto autobiográfico, si no como la antificción lejeuniana a la que alude, sí como una no-ficción, empleando este término de la bibliografía anglosajona — non-fiction- - Hasta tal punto es así, que el contrato de la autonarración se asemeja mucho al pacto propuesto por Lejeune:

La autonarración implica un contrato de lectura claro y abiertamente referencial. No se trata de contentarse con la correspondencia entre el nombre del autor y el del narrador (podemos prescindir de ella, como en el caso de Henry Roth), sino de llevar más lejos el paralelismo entre la vida transcrita en el texto y la vida empírica del autor (Schmitt, 2010b).

Lo que diferencia, en definitiva, la autonarración de Schmitt de la autobiografía de Lejeune es que en la primera se asume la "ambición utópica" que supone comprometerse a expresar el plano referencial "en su totalidad biográfica” (Schmitt, 2010b).

Al mismo tiempo, la autonarración se diferencia de la autoficción en la medida en que esta última no propone ningún contrato referencial. Es justo al final de este artículo (Schmitt, 2010b) cuando se evidencia que la autonarración no es exactamente autobiografía, pero sobre todo no es autoficción, que Schmitt prefiere denominar como ficción de lo real. Es decir: por mucho que lo autoficcional abunde en lo ficcional, según su perspectiva lo autoficcional también debe distinguirse de lo novelístico, además de sosteniendo esa identidad entre autor y narrador, respetando de algún modo su parte referencial. Sería, a diferencia de Gasparini, una manera de asumir la autoficción como un descendiente posmoderno de la autobiografía. La tesis fuerte de Schmitt, que explica en los dos artículos citados y publicados en 2010, es que la experiencia de lo autoficcional no puede quedar, para el lector, en un terreno neutro, en donde el texto ni es verdadero ni falso. Por este motivo, él prefiere incidir en el carácter referencial de lo autoficcional, aunque asume la complejidad de su empresa: "Poner el acento en el aspecto referencial de un género que se ha esforzado por no rendir demasiada cuenta a la realidad y por hacer

\footnotetext{
${ }^{8}$ Todas las traducciones de los textos de Arnaud Schmitt son mías.
} 
repetidas encarnaciones en el ámbito de lo ficticio, equivale a dar una definición contraria a las elaboradas desde que la palabra "autoficción" apareció" (Schmitt, 2010b).

En el último trabajo que Schmitt ha publicado sobre el tema, en el año 2020, señala que el debate sobre lo autoficcional, a pesar de sus esfuerzos y los de otros teóricos, todavía está abierto, definiéndolo al modo policial como "un caso sin resolver" (Schmitt, 2020: 1), y asegura que su postura teórica sigue siendo la misma que en 2007 (Schmitt, 2020: 5). Según esta, Schmitt entiende como imposible la lectura híbrida de lo autoficcional, aquella que propugna su carácter indecidible entre lo ficcional y lo referencial, y explica que esta última visión solamente tiene éxito por cuanto el "antiesencialismo es más 'sexy' que la definición de fronteras rígidas" (Schmitt, 2020: 5). En este artículo retoma sus tesis de "Making the Case for Self-Narration Against Autofiction" para reconocer que en ese momento escribía motivo por un espíritu de sobreprotección respecto a la escritura autobiográfica o, tal y como la denomina, lifewriting. Una vez que la moda autoficcional se apaga, como él mismo sugiere, le interesa destacar los aspectos positivos que posee el discurso autoficcional dentro de lo que denomina la novela autobiográfica. A partir de esta perspectiva reconoce que, si durante mucho tiempo el requisito de identificación - explícita o implícita - entre autor y narrador para definir el texto autoficcional le pareció una condición accesoria e innecesaria, ahora cobra otra perspectiva en la medida en que funciona como un elemento diferenciador en "la contribución de la autoficción a la historia de la novela autobiográfica" (Schmitt, 2020: 8). Si algo hace de la autoficción un subgénero propio es configurarse como "una forma hiperbólica de la novela autobiográfica" (Schmitt, 2020: 9), y el modo en que lo hace es llamar la atención de un lector que, a diferencia de lo que ocurre en ese tipo de novelas, se ve impelido por esta identificación entre autor y lector, y por una serie de pistas e indicios autobiográficos que lo mantienen en un espacio narrativo de juego y parodia. Tanto esta identificación como el juego establecido por el autor conllevan además "una mayor responsabilidad hacia la realidad" (Schmitt, 2020: 9) que la que se establece en la novela autobiográfica, por lo que, según Schmitt, lo autoficcional estaría un paso más cerca de lo autobiográfico que esta última. Como conclusión a todo esto, llega a la noción de "avatar", que según él diferencia al Yo autoficcional del Yo de la novela autobiográfica:

Un avatar de autoficción es un ubicuo "yo" progresivamente desprendido de la realidad fáctica del autor, mientras que un "yo" ocasionalmente autobiográfico dentro de una novela es como una referencia lejana a uno mismo, una que puede ser fácilmente extrañada por los lectores y no tiene una importancia vital; cuando se trata de la autoficción, esta referencia a uno mismo es la razón de ser de la obra y apuntala su propia existencia (Schmitt, 2020: 10).

En esto último pueden radicar las claves de diferenciación entre lo autoficcional y la novela autobiográfica que propone Schmitt, pero también la definición final de la autoficción. Esta, sostiene él, se ha interpretado frecuentemente desde un punto de vista 
erróneo según el cual "no hay una diferencia fundamental entre un texto narrativo y uno ficcional", lo que provoca que "la autoficción quede obsoleta" en tanto que esta etiqueta depende evidentemente de la "tensión que crea al jugar con la brecha entre las premisas de un texto y su elaboración ficticia" (Schmitt, 2020: 11). En otras palabras: si no hay diferencia entre la narración y la ficción, o si toda narración es entendida como ficción, la propia etiqueta de autoficción deja de tener sentido. Lo que igualmente sucede si lo autoficcional es entendido como otra forma estrictamente autobiográfica. Para Schmitt, la clave de la autoficción reside en levantar un texto que tensione tanto la naturaleza autobiográfica como el estatus ficcional del texto para situarse en el terreno de la ficción autobiográfica con una singularidad crucial, que es la que pretende resumir con ese avatar. A partir de esto último, el Yo autoficcional se desprende de la realidad fáctica del autor, se modela sin compromiso referencial en el texto ficcional y se convierte en centro del relato literario, algo que no sucede en lo que entiende por ficción autobiográfica.

Con este artículo de 2020, en definitiva, Schmitt termina de mostrar su posición acerca de los espacios diferenciados entre discurso autobiográfico y discurso ficcional, por un lado, y la autonarración y la autoficción por otro.

Para redondear esta teoría, además, me voy a referir brevemente a sus hipótesis sobre la escritura autobiográfica concentradas en su libro de 2017 titulado The phenomenology of autobiography (Schmitt, 2017) y resumidas en un artículo de 2018, "From Autobiographical Act to Autobiography". La idea fundamental de estos textos respecto a lo autobiográfico es que, frente a lo que en muchas ocasiones se ha pensado, la autobiografía es una modalidad, pero no un género literario. Para demostrar esto, Schmitt repasa en su artículo las diferentes formas en que el ser humano emplea herramientas propias del espacio autobiográfico y llega a la conclusión de que debe diferenciarse entre la simple narración autobiográfica y el medio que sistematiza el acto autobiográfico y lo convierte en una autobiografía (Schmitt, 2018: 479). Este último proceso comporta una serie de elementos que están ausentes en el acto cotidiano de la autobiografía - que puede suceder en cualquier momento de la vida del individuo-, como puede ser el riesgo a la hora de narrar la vida propia, la suerte de encontrar una recepción adecuada etc. Por parte de Schmitt (2018: 483), es otra manera de decir que existe un grado cero de lo autobiográfico al que se superpone un nivel superior, que estaría representado por la autonarración y que se define, en suma, por esa sistematización de los materiales autobiográficos puros. Esta idea de lo autobiográfico termina de configurar el sistema de Schmitt. Dentro de este último, puede encontrarse lo autobiográfico y lo ficcional en cada uno de los extremos, y en esa misma línea se situaría la autonarración, más cercana a lo autobiográfico, y a continuación la autoficción, más próxima evidentemente a lo ficcional. 


\subsection{Las tesis de Vera Toro: la ficción del texto autobiográfico}

Vera Toro es una investigadora de la Universidad de Bremen que ha escrito uno de los ensayos más actualizados sobre literatura autoficcional en el contexto hispánico. Me refiero a El concepto poetológico de la autoficción en la narrativa hispánica, publicado en 2017. Aunque la autora estudia estas escrituras en otros textos, me voy a centrar en algunas ideas de este ensayo que resultan, a mi modo de ver, fundamentales para entender las diferencias entre autobiografía y autoficción.

En este libro, Toro lleva a cabo una larga y minuciosa introducción teórica a propósito del concepto de autoficción y, entre otras cosas, en ella intenta dilucidar unos límites del mismo. Frente a la propuesta híbrida de algunos teóricos que ya denunciaba Schmitt, Toro propone hacer hincapié en el carácter "extremadamente ficcional" de la autoficción. Para ello parte de una base que puede resultar muy aclaratoria en la medida en que intenta resolver el supuesto carácter indecidible de lo autoficcional: así, Toro considera inapropiado "hablar de una mezcla entre (el pacto de) novela y (el pacto de ) autobiografía en una autoficción" (Toro, 2017: 46) y prefiere centrar el carácter de la autoficción en lo que tiene de texto evidentemente ficcional, por lo que intenta matizar las diferencias, en terminología genettiana (Genette, 1993), entre lo factual -dominio de lo autobiográfico - y lo ficcional — dominio de la novela —. En este punto, Toro llega a una de las claves de su tesis y para ello se basa en las posiciones del teórico alemán Werner Wolf. Este último distingue entre la fictio y el fictum: la primera se refiere al "aspecto de la ficción que enfoca su carácter de artefacto — de constructo- en contraste con la realidad naturalmente dada" (Toro, 2017: 52); la segunda al "aspecto que enfoca la 'irrealidad', la falta de referencia a algo realmente existente en el mundo extratextual" (Toro, 2017: 52). Asumiendo esta distinción, utiliza ambos elementos para advertir de que el texto factual y autobiográfico cuenta con "el carácter de constructo y la artificialidad" de la fictio, pero no con la falta de referencia del fictum; el texto ficcional, a diferencia del factual, cuenta con las dos (Toro, 2017: 52). Y llega a la siguiente conclusión:

[...] mientras el carácter de constructo y la artificialidad del texto autobiográfico, de cualquier narración de memorias como la composición y escenificación intencionada del yo narrado (el aspecto fictio), permanece incontestada, la veracidad y referencialidad general de los hechos narrados goza de independencia absoluta de ello (el aspecto fictum no entra cuestión). [...] En este aspecto contractual sería posible comparar la escritura autobiográfica (sincera) con la memoria autobiográfica. Ambos carecen del aspecto fictum por tener como objetivo la comunicación de manera más fiel posible a la realidad [...]. Como se ha podido demostrar, no puede haber obviamente ninguna autobiografía sin ficción, pero esta es de carácter existencial e inevitable y carece del estatus fictum, constitutivo de la ficción literaria (Toro, 2017: 52-53).

Toro explica con claridad, pues, la diferencia que existe entre lo autobiográfico, en donde se pone en marcha solo un tipo de ficción - la fictio, la que se deriva del proceso 
de sistematización de lo autobiográfico al que aludía Schmitt-, y la ficción literaria pura. Como derivación de ello, Toro sitúa lo autoficcional en este último terreno, pues, y aquí radica la segunda parte de esta teoría diferencial, la autoficción, para ser tal, debe mostrar una ficcionalidad evidente. Así lo señala:

[...] la autoficción, según mi concepto (y el de Colonna), no se ubica en una rara zona fronteriza entre textos que por su apariencia podrían pasar por factuales (en estos casos y solo en ellos serviría de algo fijarse en indicios de ficción). Más bien se ubica en la zona de textos extremadamente ficcionales; su ficcionalidad se remata ya de por sí a través de recursos narrativos múltiples paradójicos, metaficcionales y antilusorios cuyo empleo se ubica genuinamente y necesariamente en textos ficcionales. En otras palabras: lo que abunda en una autoficción son indicios (explícitos o implícitos) de su ficcionalidad (Toro, 2017: 37).

A lo largo de su ensayo, Toro complementa esta definición con los diferentes elementos que pueden - incluso deben, según lo que sostiene en ocasiones - encontrarse en un texto para que este pueda ser considerado autoficcional. Por referirme a lo que me interesa ahora, lo más relevante es que Toro diferencia tajantemente entre ambos discursos, y además se atreve, lo que no es usual en la teoría sobre escritura autobiográfica, a explicar por qué. Para ello fusiona los aspectos pragmático - el contrato referencial - y performativo - ficcional — de la escritura autobiográfica, que en última instancia puede funcionar como cualquier relato ficcional. Lo que la diferencia de la escritura ficcional y autoficcional, en definitiva, es que en el discurso autobiográfico no se despliega el fictum, que puede interpretarse como el sistema de signos que suspende e invalida la condición referencial de un texto. Dentro de este sistema, Vera Toro reúne elementos como el carácter metaficcional y autoconsciente o el juego humorístico y paradójico que despliega el texto autoficcional, componentes que le otorgan al texto no ya una subversión del pacto autobiográfico, sino un pacto nuevo, novelesco y completamente —ostentosamente, añade Toro- ficcional (Toro, 2017: 108).

Partiendo de las teorías de Toro, puede comprobarse cómo el texto autobiográfico sí desarrolla un tipo de ficción que no es necesariamente la ficción del texto novelístico puro, por decirlo así; mientras que este último posee la doble naturaleza de la fictio y el fictum, el primero, toda vez que se trata de un artefacto textual y también referencial, solo posee el fictum. Esto facilita la interpretación del texto autobiográfico como un texto con un determinado carácter ficcional, lo que al mismo tiempo permite explicar su naturaleza narrativa y finalmente literaria.

\section{CONCLUSIONES}

En una fecha tan temprana como 1957, Northrop Frye (1990: 303) establece una relación de semejanza entre lo autobiográfico y lo ficcional que viene a resumir la posición de muchos teóricos desde la proliferación de los estudios sobre escritura autobiográfica en los años 70 y 80 . Esa confusión se mantiene en muchos ámbitos hasta 
la propia actualidad, si bien en los últimos años, a propósito de la decadencia de lo autoficcional, cada vez más autores tienden a diferenciar entre discurso autobiográfico y autoficcional. Aquí se han desarrollado dos grandes posiciones, como las de Arnaud Schmitt y Vera Toro, y se han resumido otras dos, como las de Gasparirini y Alberca, y en todas ellas - ya sea las que privilegian lo autobiográfico, como la de Alberca, o lo autoficcional, como la de Gasparini- se distingue entre las dos formas de afrontar estas escrituras del Yo.

De todo lo anterior, me interesa rescatar las novedades más interesantes de las aportaciones explicadas, sobre todo las que se refieren a la naturaleza de lo autobiográfico, dado que partir de la definición de este último espacio puede colegirse, también, el ámbito de lo autoficcional y sus fronteras. Respecto al primer tipo de escritura, parece existir cierto consenso en atribuir a lo autobiográfico un contrato propio, resumido a grandes rasgos en el pacto de Lejeune, y según el cual existe la posibilidad por parte del autobiógrafo de escribir un texto referencial, en el que se produzca una correspondencia entre lo vivido y lo narrado transmisible a partir de ese acto ético que es toda obra autobiográfica. Tal es la postura de Alberca y Schmitt, que sin embargo diverge en el modo de entender el espacio autobiográfico. En el primer caso, Alberca opta directamente por defender el concepto lejeuniano de la antificción, para destacar y valorar el riesgo tomado por el autobiógrafo, que es precisamente aquello que lo diferencia del escritor de autoficciones, terreno en donde no existe riego ni compromiso alguno. En el caso de Schmitt, este también está de acuerdo en el riesgo que debe implicar - e implica- el verdadero texto autobiográfico, pero en su caso asume las diferencias entre el acto autobiográfico y la autobiografía, y en última instancia se centra en aquello que convierte a la segunda en una sistematización de lo anterior, con las diferencias que conlleva. Así llega al concepto de autonarración, con el que pretende englobar aquellos textos que, cumpliendo el pacto referencial y por lo tanto estableciendo una identidad y coherencia autobiográfica entre autor, narrador y personaje, aspiran a construir un relato de interés literario, en muchas ocasiones modelado con estructuras propias del relato novelesco. La autonarración se situaría, dentro del terreno de lo autobiográfico, entre la autobiografía y la autoficción, pero más cercana a la primera y solo diferenciándose de ella en la medida en que su autor asume la imposibilidad de reflejar la totalidad biográfica en un texto. Además, y esto lo asemeja a Alberca y Lejeune, Schmitt incide en su idiosincrasia como texto pertenecientre a la no-ficción. Respecto a la autoficción, la considera dentro de la novela autobiográfica, asumiendo las diferencias respecto a esta en la medida en que el texto autoficcional, sostiene, posee una mayor responsabilidad respecto a lo autobiográfico; por este motivo en este tipo de textos se mantiene la identificación entre autor, narrador y personaje, y se hace del Yo protagonista, modelado a partir de la ironía y la paradoja, el centro del relato - algo que no sucede en la novela autobiográfica-.

La postura que termina de redondear esta diferenciación es la de Vera Toro, que plantea una distinción muy bien trenzada entre autobiografía y autoficción. Según Toro, el texto autobiográfico no se encuandra exactamente dentro de la no-ficción, pues en la 
medida en que el autor emplea una plataforma textual para narrar su vida esta última se ficcionaliza, si bien no da como resultado el mismo tipo de ficción que la ficción pura y, en este caso, la autoficción. Como se ha explicado, la autobiografía de Vera Toro posee una sustancia ficcional relacionada con la capacidad que todo texto tiene para desplegar un campo referencial propio, ajeno al espacio biográfico, pero también carece de la entidad ficcional que posee el texto exclusivamente fabulado. Este, según Toro, es el terreno de lo autoficcional, que para conformarse como tal tiene que exhibir un carácter ampliamente ficcional.

Esta última sería, a mi parecer, la posición más adecuada para entender la naturaleza del texto autobiográfico. Aunque se pueden establecer matizaciones y diferentes gradaciones entre los dos extremos, tal y como hace Schmitt con los conceptos de autonarración y autoficción, en última instancia siempre hay un elemento que separa el texto autobiográfico del texto autoficcional, y es el pacto ético que el primero firma y el segundo deja en suspenso. Por lo demás, las características que normalmente separan ambos textos - la ironía, la paradoja o la explotación de las contradicciones del Yo refrencial en el caso del discurso autoficcional - son de carácter accesorio, y en última instancia es el aspecto paratextual lo que diferencia una escritura de la otra. Cuando esto último se produce, la autobiografía puede ser entendida como un texto con rasgos ficcionales como los destacados por Vera Toro, pero nunca como un texto absolutamente ficcional. Es, sobre todo, un texto referencial.

Establecida esta suerte de ley, debe quedar claro que cada texto ofrece sus propias coordenadas de interpretación. Tal debe ser la norma del crítico ante este tipo de obras: cada una de ellas ofrece un determinado contexto de análisis y diferentes formas de afrontar los fenómenos descritos más arriba. Por ejemplo, en el caso de la literatura española reciente es interesante detenerse en la obra diarística de Andrés Trapiello (Luque Amo, 2020), que abunda en las cuestiones más polémicas del debate anterior. Es una obra compleja, entre otras cosas, porque el autor ha sostenido en numerosas ocasiones que sus diarios se inscriben dentro del ámbito ficcional, y que son en realidad una novela en marcha. Sin embargo, tanto el lector como el crítico saben que se trata de diarios autobiográficos, e incluso en ocasiones el propio autor reconoce tal naturaleza. Ante el problema, y como desarrollo pormenorizadamente, sostengo una lectura referencial de un texto que se ve comprometido, a través de varios paratextos en los que participa el autor, como texto autobiográfico. Aunque Trapiello reconoce que en ocasiones algunos pasajes son fabulados, el conjunto de la obra se enmarca dentro del espacio autobiográfico, $\mathrm{y}$, como sostienen tanto Alberca como Toro, no basta con mentir para que un texto autobiográfico sea considerado autoficcional. A su vez, y apoyándome ahora en Schmitt, puedo definir el diario de Trapiello como una autonarración, porque el autor muestra una clara conciencia de las limitaciones de la empresa autobiográfica y, al mismo tiempo, una ambición por hacer de su texto una obra literaria. Trapiello incorpora todo tipo de elementos para novelizar su diario, pero en última instancia en este se cumple una identificación entre autor, narrador y personaje, así como un contrato implícito entre autor 
y lector mediante el que el primero se compromete a escribir una narración en la que los acontecimientos, por lo general, son verídicos. Los diarios de Trapiello se conforman, por tanto, como una autobiografía narrada: una autonarración.

Otros ejemplos de lo anterior en la literatura española contemporánea, por mencionar algunos sin ofrecer un análisis exhaustivo - que excedería la dimensión de este trabajo-, pueden encontrarse en obras de carácter variado. Es muy ilustrativo a este respecto el libro autobiográfico de Jorge Semprún, La escritura o la vida, donde este construye en clave novelística una autobiografía con un tono confesional muy evidente. La forma en que Semprún aborda el relato autobiográfico manifiesta su intención de novelizar sucesos biográficos, acaecidos realmente, que permanecen como tales; es decir, la obra no cae en ningún momento en el relato fabulado e incluso, a diferencia de su Autobiografía de Federico Sánchez —que en algunos aspectos también podría interpretarse como una autonarración indirecta-, apuesta por ofrecer una identificación explícita entre autor, personaje y narrador. Un caso anterior, paradigmático en la literatura catalana y que se constituye como una de las obras más importantes del ámbito ibérico, es El quadern gris de Josep Pla (1966). En esta obra, Pla presenta un supuesto diario personal que mantiene desde su juventud, con todas las fechas y las entradas indicadas, pero, como ha demostrado Xavier Pla (1996), se trata de un falso diario personal, absolutamente reconstruido, que en última instancia forma una autobiografía verdadera - pues los sucesos y el mundo que construye Pla son ciertos y pertenecen a su propia biografía - Esta construcción de una autobiografía referencial por medio de técnicas novelísticas, en definitiva, es uno de los mayores ejemplos de lo que se puede llamar autonarración en España. De hecho, en muchas ocasiones se ha catalogado El quadern gris como un diario - sin ser un diario autobiográfico — o como una autobiografía — sin tener la estructura de la autobiografía o las memorias-, y es muy posible que el concepto de autonarración describa la empresa de Pla de forma mucho más efectiva. En el contexto internacional, además, en los últimos años está despuntando una obra autobiográfica descomunal, publicada en seis tomos, como es la del escritor noruego Karl Ove Knausgaard bajo el título general de Mi lucha. En esta obra, y tal y como he intentado demostrar en otro lugar (Luque Amo, 2019), el escritor noveliza su vida, construyendo una autobiografía que respeta el pacto lejeuniano y que, al tiempo, se conforma mediante diversos discursos novelísticos, dado que en ingún caso el relato es lineal, ni se basa en una estructura clásica de la autobiografía. Más que autobiografía al uso, y sin llegar a conformarse como autoficción — pues no introduce ningún elemento pretendidamente fabulado-, Mi lucha es sobre todo una autonarración.

Lo escrito hasta ahora permite diferenciar a grandes rasgos entre los espacios autobiográfico y autoficcional. Retroceder hasta la carta de Doubrovsky a Lejeune ha posibilitado, en suma, dejar constancia de las diferencias que ya existen entre ambos tipos de escritura desde el origen de la propuesta autoficcional, pues el fenómeno autoficcional surge ligado a la autobiografía y, al mismo tiempo, se diferencia de ella hasta ocupar un espacio propio. Una vez explicada la evolución del concepto hasta la actualidad, se ha 
comprobado que estas fronteras no siempre han estado claras y que es precisamente en los últimos años, mientras lo autoficcional pierde fuerza como moda literaria, cuando los estudios tienden a establecer límites tajantes entre los dos modos de escritura. Frente a lo que en ocasiones se ha pensado, estos límites no constriñen la obra literaria, sino que, por el contrario, arrojan luz sobre unos textos que en muchas ocasiones, y precisamente en el intento de subvertirlas, refuerzan estas fronteras, motivo por el que es necesario establecer un análisis individual de cada obra a partir de un marco teórico, claro y sólido, como el que aspiro a proporcionar —o reforzar- con el presente trabajo.

\section{REFERENCIAS BIBLIOGRÁFICAS}

AlBerca, M. (1996). "El pacto ambiguo". Boletín de la Unidad de Estudios Biográficos $1,9-18$.

(2007). El pacto ambiguo: de la novela autobiográfica a la autoficción. Madrid: Biblioteca Nueva.

(2009). "Es peligroso asomarse (al interior). Autobiografía vs. Autoficción". Rapsoda 1, 1-24.

(2014). "De la autoficción a la antificción. Una reflexión sobre la autobiografía española actual”. En El yo fabulado. Nuevas aproximaciones críticas a la autoficción, Ana Casas (introducción, compilación de textos y bibliografía), 149168. Madrid / Frankfurt: Iberoamericana-Vervuert.

(2017). La máscara o la vida. De la autoficción a la antificción. Málaga: Pálido Fuego.

Caballé, A. (2017). “Cansados del yo?”. El País, 6 de enero. Disponible en línea: https://elpais.com/cultura/2017/01/06/babelia/1483708694_145058.html [17/01/2021].

CASAS, A. (2012). "El simulacro del yo: la autoficción en la narrativa actual". En La autoficción. Reflexiones teóricas, Ana Casas (introducción, compilación de textos y bibliografía), 9-44. Madrid: Arco / Libros.

DARRIEUSSECQ, M. (2012). "La autoficción, un género poco serio". En La autoficción. Reflexiones teóricas, Ana Casas (introducción, compilación de textos y bibliografía), 65-82. Madrid: Arco / Libros.

DE MAn, P. (1991). “La autobiografía como des-figuración”. Anthropos 29, 113-118.

Doubrovsky, S. (2001). Fils. París: Gallimard.

(2012). “Autobiografía / verdad / psicoanálisis". En La autoficción. Reflexiones teóricas, Ana Casas (introducción, compilación de textos y bibliografía), 45-64. Madrid: Arco / Libros.

Frye, N. (1990). Anatomy of criticism. London: Penguin Books.

GASPARINI, P. (2011). "Enjeux critiques des écritures (auto)biographiques contemporaines". Tangence 97, 11-24. 
GenetTe, G. (1993), Ficción y dicción. Barcelona: Lumen.

Laín Corona, G. y Santiago Nogales, R., eds. (2019). Teatro, (auto)biografía y autoficción (2000-2018) en homenaje al profesor José Romera Castillo. Madrid: Visor Libros.

LECARME, J. (1984). "Fiction romanesque et autobiographie". En Universalia. Encyclopaedia Universalis, 417-418. Paris: Encyclopaedia Universalis.

LEJEUNE, P. (1994). El pacto autobiográfico y otros estudios. Madrid: Megazul. (2007). "Le journal comme 'antificion"”. Poétique 1.149, 3-14.

LOUREIRo, Á. G. (2016). Huellas del otro. Ética de la autobiografía en la modernidad española. Madrid: Postmetropolis.

LuQue Amo, Á. (2019). “Coraje de la verdad y escritura autobiográfica en La muerte del padre de Karl Ove Knausgård”. Tropelías 5, 110-119. (2020). El diario literario: poética e historia. Berlín: Peter Lang.

MARÍAS, J. (2001). Literatura y fantasma. Madrid: Alfaguara.

Molero DE LA IGLESIA, A. (2006). "Figuras y significados de la autonovelación". Espéculo 33, s. p. Disponible en línea:

http://webs.ucm.es/info/especulo/numero33/autonove.html [30/06/2021].

MorA, V.L. (2019). La huida de la imaginación. Valencia: Pre-Textos.

Pla BARbero, X. (1996), "El autobiografismo ficcional en la obra de Josep Pla". En Mundos de ficción, J. M. Pozuelo Yvancos y F. V. Gómez (eds.), 1229-1236. Murcia: Universidad de Murcia.

Pozuelo Yvancos, J. M. a (1993). Poética de la ficción. Madrid: Síntesis. (2010). Figuraciones del yo en la narrativa: Javier Marías y E. Vila-Matas. Valladolid: Cátedra Miguel Delibes.

REYNOLDS, S. (1906). “Autobiografiction”. Speaker 15.366, 28 \& 30.

Romera CASTILlo, J. (1981). "La literatura, signo autobiográfico. El escritor, signo referencial de su escritura”. En La literatura como signo, J. Romera Castillo (ed.), 13-56. Madrid: Playor.

(1991). "Panorama de la literatura autobiográfica en España (1975-1991)". Anthropos 29, 170-184.

(1999). "Estudio de la escritura autobiográfica española (Hacia un sintético panorama bibliográfico)". En Escritura autobiográfica y géneros literarios, Manuela Ledesma Pedraz (ed.), 35-52. Jaén: Universidad de Jaén.

(2006). De primera mano. Sobre escritura autobiográfica en España (siglo XX). Madrid: Visor Libros.

(2010). “La escritura (auto)biográfica y el SELITEN@T: guía bibliográfica”. Signa 19, 333-369.

Romera CASTILlo, J. et ALII, eds. (1993). Escritura autobiográfica. Madrid: Visor Libros.

SAUNDERS, M. (2009). “Autobiografiction: Experimental Life-Writing from the Turn of the Century to Modernism". Literature Compass 6.5, 1041-1059. 
SchmitT, A. (2005). "Auto-narration et auto-contradiction dans Mercy of a Rude Stream d'Henry Roth". Annales du CLAN 29, 181-196.

(2010a). "Making the Case for Self-narration Against Autofiction". $a / b$ : Auto/Biography Studies 21.1, 122-137.

(2010b). "De l'autonarration à la fiction du réel: les mobilités subjectives". En Autofiction(s), C. Burgelin, I. Grell et R.-Y. Roche (eds.), s. p. Lyon: Presses Universitaires de Lyon. Disponible en línea: https://doi.org/10.4000/ books.pul.3741 [17/01/2021].

(2017). The Phenomenology of Autobiography: Making it Real. New York: Routledge.

(2018). "From Autobiographical Act to Autobiography". Life Writing 15, 4, 469486.

(2020). "Avatars as the Raison d'Être of Autofiction". Life Writing 0, 1-12.

Toro, V. (2017). Soy simultáneo: el concepto poetológico de la autoficción en la narrativa hispánica. Madrid: Iberoamericana.

Wagner-EgelhaAf, M., ED. (2009). Handbook of Autobiography/Autofiction, 3 vols. Berlin / Boston: De Gruyter.

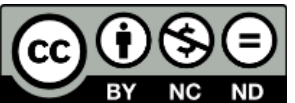

This work is licensed under a Creative Commons AttributionNonCommercial-NoDerivatives 4.0 International (CC BY-NC-ND).

Fecha de recepción: 02/02/2021

Fecha de aceptación: 30/06/2021 